\title{
Arka Noego a opisy potopu w tekstach sumeryjskich i akadyjskich
}

\author{
AndrzejJ. Obidowicz
}

Kraków

obidowa@onet.pl (1) https://orcid.org/0000-0003-1429-3724

Biblijny opis potopu zawarty w Księdze Rodzaju jest wynikiem połączenia przez redaktora dwóch tradycji - jahwistycznej (J) oraz kapłańskiej (P) w jedno opowiadanie. Instrukcja dotycząca budowy arki - w szczególności dotycząca jej budulca - zawarta jest w wersecie Rdz 6, 14, który egzegeci przypisują tradycji kapłańskiej ${ }^{1}$. Noe otrzymuje polecenie zbudowania arki (תֶָָ tebah). To hebrajskie słowo oznacza „pojemnik”, zastosowane zostało także do trzcinowego koszyka służącego do ocalenia Mojżesza (Wj 2, 3. 5). Septuaginta oddaje ten termin słowem кı $\beta \omega \tau$ ć („,skrzynia”), a Wulgata - arca. Wers Rdz 6, 14 w Biblii Hebrajskiej brzmi:

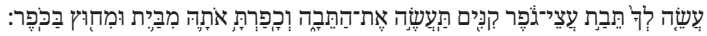

Anna Kuśmirek tłumaczy ten fragment:

Uczyńsobiearkę(z)drzewagofer,przegrodyzrób(w)arcei posmołujjąz wewnątrzi zzewnątrzsmołą ${ }^{2}$.

\section{Budulec arki}

Tekst hebrajski podaje jako budulec arki drzewo גֶֶ gofer. Biblia Tysiąclecia przekłada to słowo wyrażeniem „drzewo żywiczne”3 - określenie to oznacza

1 T. Brzegowy, Pięcioksiąg Mojżesza. Wprowadzenie i egzegeza Księgi Rodzaju 1-11, Tarnów 1998, s. 216; A. Läpple, Od Księgi Rodzaju do Ewangelii. Wprowadzenie do lektury Pisma Świętego, przeł. J. Zychowicz, wyd. 2, Kraków 1983, s. 121.

2 Księga Rodzaju. Hebrajsko-polski Stary Testament. Wydanie interlinearne z kodami gramatycznymi, transkrypcją oraz indeksem rdzeni, przekł. i oprac. A. Kuśmirek, Warszawa 2000.

3 Pismo Święte Starego i Nowego Testamentu w przekładzie z języków oryginalnych, opracował zespół biblistów polskich z inicjatywy Benedyktynów Tynieckich, wyd. 5, Poznań 2014. 
drewno zaimpregnowane przez swój naturalny składnik (żywicę). The Bible. New International Version ma „cypress wood” („drewno cyprysowe”). Takie drewno jako materiał arki podaje także targum do Księgi Rodzaju. Tekst Septuaginty nie wymienia gatunku drewna, natomiast podaje, iż Noe miał wykonać arkę z foremnych bali o przekroju kwadratu. W oparciu o tekst biblijny nie jest możliwe określenie budulca arki, gdyż słowo gofer to hapax legomenon. Wolf Gunther Plaut uważa, iż słowo to określa gatunek nadal niezidentyfikowany ${ }^{4}$.

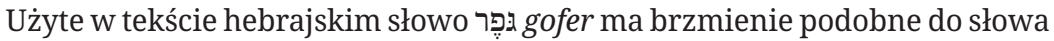

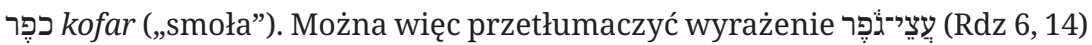
jako „drzewo smołowane”. Ponadto Septuaginta stosuje w Rdz 6, 14 słowo ả $\sigma \varphi \alpha \lambda \tau \omega \dot{\sigma} \sigma \varepsilon \iota$ - „pokryjesz asfaltem”. Użycie w przekładzie Rdz 6, 14b wyrażeń „drewno cyprysowe” lub „drzewo żywiczne” jest więc nieuzasadnione, zaś właściwym tłumaczeniem jest: „drewno pokryte smołą (asfaltem)”.

\section{Powstanie arki według Księgi Rodzaju i Eposu o Gilgameszu}

Zamieszczony w Księdze Rodzaju opis arki rodzi niepokonalne trudności interpretacyjne. W wyniku połączenia tradycji jahwistycznej (J) oraz kapłańskiej (P) dokonanego przez redaktora księgi biblijny opis potopu zawiera sprzeczne dane o ilości zwierząt zabranych przez Noego do arki.

Rdz 6, 19 (P): „A z wszystkiego co żyje, z wszelkiego ciała (po) dwoje z wszystkiego przyprowadzisz”.

Rdz 7, 2 (J): „Ze wszelkiego bydła weź czystego (ze) sobą (po) siedem, siedem (razy) samca i samicę jego, a z bydła, które nie nie (jest) czyste (po) dwoje samiec i jego samica”.

Badania tekstów sumeryjskich oraz akadyjskich sugerują, że autor biblijnego opisu potopu mógł zaczerpnąć informacje dotyczące arki z Eposu o Gilgameszu ${ }^{6}$. Z tego względu interesujące wydaje się omówienie opisu potopu zawartego w tym opowiadaniu.

4 W. G. Plaut, The Torah. A Modern Commentary, t. 1: Genesis, New York 1974, s. 63.

5 Cyt. za: Księga Rodzaju. Hebrajsko-polski Stary Testament..., dz. cyt.

6 Na temat zależności literackiej fragmentu biblijnego opisu potopu od sumeryjskiego dokumentu tzw. Recenzji z Nippur por. A. J. Obidowicz, Biblijny opis potopu a dokumenty mezopotamskie, „Ruch Biblijny i Liturgiczny” 57 (2004) nr 1, s. 5-10, https://doi.org/10.21906/rbl.482. 
Najstarszy utrwalony tekst eposu zapisano w języku akadyjskim - datowany jest na drugie tysiąclecie i określany przez współczesnych specjalistów jako wersja starobabilońska - zapis ten jest znacznie uszkodzony. Wersja późniejsza składa się z 12 tablic, zachowała się w lepszym stanie, została skomponowana około XIII wieku przed Chrystusem i jest określana współcześnie jako wersja standardowa ${ }^{7}$. Opis potopu zawarty jest na tablicy jedenastej (Gi XI) tej wersji. Gi XI stanowi relację z przebiegu potopu, którą bohaterowi eposu, królowi Gilgameszowi z Uruk, opowiada jego przodek Utnapisztim. Według tej relacji bóstwo o imieniu Ea poleciło Utnapisztimowi:

Wejdź na pokład statku, weź sobie potomstwo wszystkiego, co żyje [NUMUM nap-ša-a-ti] (Gi XI 27).

NUMUM - nasienie, potomstwo

napištu - życie ${ }^{9}$

Gi XI 27 zawiera zatem nakaz zabrania na pokład „wszystkiego, co żyje”. Jednakże wersety Gi XI 83 i 85 zawierają wypowiedź Utnapisztima, który stwierdza, iż wprowadził do arki bydło (bulu) oraz zwierzęta gospodarskie (umamu):

Cokolwiek miałem z potomstwa żywych stworzeń, zabrałem do wnętrza jej [arki] (Gi XI 83) ${ }^{10}$. Wszystko bydło [bu-ul EDIN], zwierzęta gospodarskie [u-ma-am EDIN] (Gi XI 85) ${ }^{\mathbf{1 1}}$.

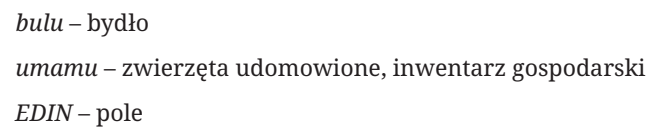

7 N. Osanai, A Comparative Study of the Flood Accounts in the Gilgamesh Epic and Genesis, „Answers in Genesis” 03.08.2005, https://answersingenesis.org/the-flood/flood-legends/flood-gilgamesh-epic/

8 Tłumaczenie na podstawie: Akkadian Myths and Epics. The Epic of Gilgamesh, translator E. A. Speiser, [w:] Ancient Near Eastern Texts Relating to the Old Testament with Supplement, ed. by J. B. Pritchard, Princenton 1978, s. 93: „Aboard the ship take thou the seed of all living things”. Transliteracja oryginału w nawiasach kwadratowych za: S. Parpola, The standard Babylonian Epic of Gilgamesh. Cuneiform text, transliteration, glossary, indices and sign list, Helsinki 1997, s. 109 (State Archives of Assyria Cuneiform Texts, 1).

9 S. Parpola, The Standard Babylonian Epic of Gilgamesh..., dz. cyt.

10 „Whatever I had of all the living beings I [laded] upon her” (Akkadian Myths and Epics. The Epic of Gilgamesh, translator E. A. Speiser, dz. cyt., s. 94).

11 „The beasts of the field, the wild creatures of the field” (tamże). 
Po terminach bulu oraz umamu występuje sumeryjski termin EDIN, co pozwala na przekład Gi XI 83-85:

Cokolwiek miałem z potomstwa żywych stworzeń, zabrałem do wnętrza arki (Gi XI 83).

Wszystko bydło z pola, inwentarz gospodarski z pola (Gi XI 85).

Powyższe fragmenty Księgi Rodzaju i Eposu o Gilgameszu mają podobny schemat opowiadania: pierwszy fragment zawiera pojęcie ogólne (Gi XI 83: „potomstwo żywych stworzeń”; Rdz 6, 19: „wszystko, co żyje”), natomiast kolejny - doprecyzowanie (Gi XI 85: „bydło z pola, inwentarz gospodarski z pola”; Rdz 7, 2: „z... bydła... samca i samicę”). Taka konstrukcja literacka jest typowa w kręgu kultury semickiej i występuje na przykład w Psalmie 78:

„Ale wystawiali na próbę i drażnili Boga Najwyższego, i Jego przykazań nie strzegli” (Ps 78, 56) ogólne przedstawienie wykroczeń Izraela.

„Pobudzali Go do gniewu przez swoje wyżyny i wzniecali Jego zazdrość swoimi rzeźbami” (Ps 78, 58) - wyszczególnienie wykroczeń Izraela.

W pierwszej części tak skonstruowanej wypowiedzi występuje pojęcie ogólne, które stanowi zapowiedź pojęcia szczegółowego, będącego jej zasadniczą treścią. Powyższa analiza pozwala uznać, że zasadnicze treści wypowiedzi Gi XI 83. 85 oraz Rdz 6, 19; 7, 2 zawarte są w określeniach szczegółowych:

Gi XI 85: „bydło z pola, inwentarz gospodarski z pola”

$\operatorname{Rdz} 7,2$ : „z... bydła... samca i samicę”

Liczba zwierząt zabranych do arki była więc znacznie ograniczona, co stawia pod znakiem zapytania tradycyjne rozumienie tej kwestii, jak również pozostaje w ścisłym związku z wymiarami arki.

\section{Wymiary arki według Księgi Rodzaju oraz Eposu o Gilgameszu}

Wymiary arki Noego podane są w Rdz 6, 15:

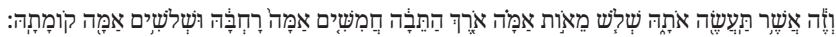


Anna Kuśmirek tłumaczy ten fragment:

A to, jak uczynisz ją: trzy setki łokci (będzie) długość arki, pięćdziesiąt łokci jej szerokość i trzydzieści łokci wysokość jej ${ }^{12}$.

Zatem Rdz 6, 15 podaje następujące wymiary arki:

- długość 300 łokci,

- szerokość 50 łokci,

- wysokość 30 łokci.

Łokieć (hebr. אֵַָ 'ammāh) to starożytna jednostka długości. Nie była zunifikowana. Rozróżniano „łokieć zwykły” (około $45 \mathrm{~cm}$ ) oraz „łokieć królewski” (około $53 \mathrm{~cm}$ ). Nie wiadomo, którą jednostkę zastosowano w tekście biblijnym, dlatego jest możliwe jedynie podanie przedziałów:

- długość arki 135,0-159,0 m,

- szerokość arki 22,5-26,5 m,

- wysokość arki 13,5-16,0 m.

Według tekstu biblijnego arka Noego stanowiła ogromną skrzynię zbudowaną siłami Noego i jego rodziny w ciągu siedmiu dni (Rdz 7, 4). Czy jest możliwe, aby wykonali oni tak duży obiekt w tak krótkim czasie?

Odczytanie wymiarów arki zapisanych w Eposie o Gilgameszu jest możliwe przy uwzględnieniu matematyki babilońskiej. Babilończycy posiadali zaawansowaną wiedzę z zakresu matematyki, jednakże fakt ten poznano dopiero około 1930 roku. Wtedy to - w wyniku odkryć archeologicznych - odnaleziono tysiące tabliczek glinianych zapisanych pismem klinowym, zawierających wiedzę z zakresu matematyki: tabele przeliczeniowe, rozwiązania problemów matematycznych oraz geometrycznych i przestrzennych. Autorami tych tabliczek byli Sumerowie oraz ich następcy Akadowie.

Do obliczania powierzchni oraz pomiaru figur geometrycznych Sumerowie stosowali jednolity system jednostek długości ${ }^{13}$ :

- šu-si (,palec”) - około 1,5 cm,

- kuš („łokieć”) - 30 šu-si - około $45 \mathrm{~cm}(50 \mathrm{~cm})^{14}$,

- gi (,trzcina”) - 6 kuš - około 2,75 m (3,00 m),

12 Księga Rodzaju. Hebrajsko-polski Stary Testament..., dz. cyt.

13 Przeliczenie jednostek na podstawie: S. N. Kramer, The Sumerians. Their history, culture and character, Chicago-London 1963, s. 107. W nawiasach podano wielkość jednostek w okresie nowobabilońskim.

14 Jednostce długości łokieć przypisywano odmienną długość w poszczególnych okolicznościach. 
- gar-du (nindanu, ninda) - 2 gi - około 5,5 m (6,5 m),

- eš („sznur”) - 10 gar-du - około $55 \mathrm{~m}$ (60 m).

Jako jednostki powierzchni stosowali:

- sar („,ogród”) - gar-du' $-35 \mathrm{~m}^{2}$,

- ikû (,pole”) - 100 sar - 3,5 tys. $\mathrm{m}^{2}$.

Istotny dla ustalenia wymiarów arki jest sumeryjski termin $i b$-si $i_{8}$ oznaczający „pierwiastek kwadratowy”, „bok kwadratu”. Termin ten posiada również znaczenia: „kwadrat” (figura geometryczna) oraz „podnosić do kwadratu”15. Znaczenia „pierwiastek kwadratowy” i „bok kwadratu” są równoważne, gdyż pierwiastek kwadratowy z danej liczby jest równy długości boku kwadratu o powierzchni równej tej liczbie.

W Eposie o Gilgameszu wymiary arki podano w wersetach 29 i 30 oraz 57 i 58 rozdziału XI:

lu-u min-du-da mi-na-tu-ša (Gi XI 29).

lu-u mit-hur ru-pu-us-ša u mu-rak-ša (Gi XI 30).

AŠ.GAN GAM-sa 10 NINDA-TA.AM u-šag-ga-a E.SIG 4 MEŠ-ša (Gi XI 57)

10 NINDA-TA.AM im-ta-hir ki-bir UGU-hi-ša (Gi XI 58) ${ }^{\mathbf{1 6}}$.

Współcześni badacze przekładają te wersety następująco:

Robert M. Best:

„Niech będą równe jej wymiary” (Gi XI 29).

„Niech będzie równy wymiar jej szerokości i jej długości” (Gi XI 30)ํ․․․

Igor Djakonow:

„Niech posiada kontur czterokąta” (Gi XI 29).

„Niech będą równe szerokość i długość” (Gi XI 30) ${ }^{\mathbf{1 8}}$.

15 O. Neugebauer, Register, Glossar, Nachträge, [w:] Mathematische Keilschrift-Texte, hrsg. und bearb. von O. Neugebauer, cz. 2, Berlin-Heidelberg 1935, s. 31 (Quellen und Studien zur Geschichte der Mathematik, Astronomie und Physik, A.3), https://doi.org/10.1007/978-3-642-67893-6_1.

16 Cyt. za: S. Parpola, The Standard Babylonian Epic of Gilgamesh..., dz. cyt., s. 109.

17 „Let-be measured its-dimensions. Let-be equal-size its-width and its-length” (R. M. Best, Translation Errors in the Gilgamesh Flood Myth, https://www.noahs-ark-flood.com/gilgamsh.htm).

18 „Очертаньем да будет четырехуголен, равны да будут ширина с длиною” (Эпос о Гильгамеше ( О все видавшем»), перевод с аккадского И. М. Дьяконова, Издательство Академии наук СССР, Москва-Ленинград 1961, s. 73). 
Nozomi Osanai:

„Jej proporcje niech odpowiadają jedna drugiej” (Gi XI 29).

„Jej szerokość i długość niech będą równe” (Gi Xi 30) ${ }^{19}$.

Powyższe zestawienie pokazuje, iż wymienieni autorzy interpretują zgodnie kształt pokładu arki jako kwadrat.

Drugi fragment (Gi XI 57-68) podejmuje kwestię wymiarów arki oraz powierzchni jejpodstawy. Interpretacje specjalistów przedstawiają się następująco:

Robert M. Best:

„Wzniosłem 120 łokci jej ściany” (Gi XI 57b).

„Dziesięć tuzinów łokci każdy wymiar krawędzi jej górnej części” (Gi XI 58)²0.

Igor Djakonov:

„Trzydzieści jego [statku] powierzchnia, burta wysoka sto dwadzieścia łokci” (Gi XI 57).

„Po sto dwadzieścia łokci krawędź jego pokładu” (Gi XI 58)21.

Nozomi Osanai:

„Jeden $i k u ̂$ była powierzchnia jej podstawy.

Podniosłem każdą z jej ścian (na) wysokość dziesięć ninda” (Gi XI 57).

„Jej [arki] pokład był kwadratem dziesięć ninda” (Gi XI 58)22.

Nozomi Osanai stosuje jednostki sumeryjskie, natomiast pozostali autorzy - współczesne. Wers 58 wszyscy autorzy interpretują zgodnie, jeśli chodzi o wielkość pokładu, Robert Best oraz Nozomi Osanai podają, że pokład miał kształt kwadratu. Igor Djakonow nie podaje kształtu pokładu w wersie 58, lecz w 30. W przekładzie Nozomi Osanai powierzchnia pokładu arki to 1 ikû (Gi XI 57), tj. 3,5 tys. m² - wynika stąd, iż każdy jej bok (skoro pokład był

19 „Her (the ship's) proportions shall correspond to each other. Her (the ship's) width and length shall be equal” (N. Osanai, A Comparison of Scientific Reliability, [w:] N. Osanai, A comparative study of the flood accounts in the Gilgamesh Epic and Genesis, https://answersingenesis.org/the-flood/ flood-legends/a-comparison-of-scientific-reliability/).

20 „Ten dozen-cubits each I-raised its-walls. Ten dozen-cubits each equal-size edges its-upper-part” (R. M. Best, Translation Errors in the Gilgamesh Flood Myth, dz. cyt.).

21 „Треть десятины площадь, борт сто двадцать локтей высотою, по сто двадцать локтей края его верха" (Эпос о Гильгамеше ("О все видавшем»), dz. суt., s. 74).

22 „One ikû was her (the ship's) floor space. I raised her (the ship’s) walls each ten ninda high. Her (the ship's) deck was ten ninda square” (N. Osanai, A Comparison of Scientific Reliability, dz. cyt.). 
kwadratem) mierzył około $60 \mathrm{~m}$. Wysokość burty wynosiła 10 ninda, czyli dziesięć tuzinów kuš (Gi XI 57), tj. około 60 m. Arka według zapisu Gi XI 57-58 stanowiła obiekt w kształcie sześcianu o bokach około $60 \mathrm{~m}$, zatem była porównywalna do 20-piętrowego budynku mieszkalnego. Trudno sobie wyobrazić wodowanie takiego obiektu, jak również zachowanie jego stateczności na wodach potopu. Z tego względu zapis Gi XI 58 należy uznać za błąd pisarza babilońskiego, który powstał w wyniku poniższych okoliczności.

Wymiary (np. długość, szerokość) przedstawiano w tekstach akadyjskich znakami sumeryjskimi, przypisując im znaczenie akadyjskie ${ }^{23}$. Znaczenie tych znaków sumeryjskich uległo przedawnieniu podczas przekazu (transmisji z języka sumeryjskiego na akadyjski) i fragmenty te stały się niezrozumiałe.

Co istotne, Robert Best, Igor Djakonov i Nozomi Osanai odmiennie tłumaczą występujący w Gi XI 58 termin kibru. Nozomi Osanai tłumaczy go na język angielski jako „square”, natomiast Robert Best i Igor Djakonov - jako „edge”. Ich przekłady nie oddają właściwego znaczenia terminu kibru. Wskazuje to na trudność w odczytaniu klinowego zapisu tej linii.

Według Nozomi Osanai Gi XI 58 możemy przetłumaczyć:

Jej [arki] pokład był kwadratem 10 ninda.

Jednak zapis dostępny kopiście akadyjskiemu posiadał inne znaczenie:

Niech pokład jej pierwiastek kwadratowy [z] 10 ninda.

Współcześnie wyraża to zapis:

Niech krawędź pokładu wynosi pierwiastek kwadratowy z 60 metrów,

co oznacza, iż długość krawędzi pokładu wynosiła około 7,6 m - taka też (Gi XI 57) była wysokość burty.

Należy więc zadać sobie pytanie, czy Utnapisztim mógł zrozumieć polecenie bóstwa:

Niech pokład jej pierwiastek kwadratowy [z] 10 ninda.

23 Historia matematyki od najdawniejszych czasów do początku XIX stulecia, t. 1, pod red. A. P. Juszkiewicza, tł. S. Dobrzycki, Warszawa 1975, s. 47. 
Obliczenie długości krawędzi pokładu wymagało od Utnapisztima umiejętności wyciągnięcia pierwiastka kwadratowego z podanej liczby, podczas gdy Gi XI 187 stosuje wobec Utnapisztima epitet atrahasis, tzn. „niezwykle mądry”. Igor Djakonow podaje znaczenie tego imienia jako „pojmujący więcej niż inni”. Gi XI nie podaje uzasadnienia tak niezwykłego polecenia, bóstwo zaleca jednak Utnapisztimowi zwrócenie szczególnej uwagi na treść przekazanej mu informacji (Gi XI 22). Znamienny jest fakt, iż została przekazana przez bóstwo imieniem Ea. Akadowie wierzyli, że wyznacza ono los człowieka, jest panem mądrości, magicznych zaklęć, patronem rzemieślników. Istotny jest również status Gilgamesza - króla Uruk. Pozwala to zasadnie domniemywać, iż również jego ojciec Utnapisztim pochodził z rodu władców i posiadał wysokie wykształcenie. W najstarszym znanym dokumencie sumeryjskim zawierającym opis potopu - tak zwanej Recenzji z Nippur - bohater ocalony przed tym kataklizmem jest królem-kapłanem. Kapłani stanowili wówczas kastę badaczy i dysponentów tajemnej wiedzy i mądrości.

Utnapisztim zrozumiał więc polecenie dotyczące wymiarów arki - mimo że zostało wydane przez Ea w niezwykłej formie:

Zrozumiałem i rzekłem do Ea, mojego pana... (Gi XI 32)

Znaczenie formuły to:

Niech pokład jej pierwiastek kwadratowy [z] 10 ninda.

Arka zbudowana przez Utnapisztima stanowiła obiekt używany przez Sumerów w rejonie ujścia dwurzecza Eufratu i Tygrysu. Na płytkich wodach tego obszaru osadnicy budowali swe trzcinowe chaty na pływających platformach uformowanych z trzciny oraz ziemi. Arka zbudowana prze Utnapisztima była właśnie taką konstrukcją - ziemia wsypana pomiędzy dolne warstwy trzciny stanowiła balast zapewniający stateczność na wodach potopu. Pośrednio o takim obiekcie pływającym jest mowa w Gi XI 79, gdyż dwie trzecie arki było zanurzone w wodzie, co oznacza, iż społeczność arki zamieszkała w pomieszczeniach o wysokości około 2,5 m - czyli wystarczającej dla ludzi oraz zwierząt gospodarskich. Również to spostrzeżenie ogranicza liczebność zwierząt zabranych na arkę oraz eliminuje dzikie zwierzęta o znacznej wysokości, np. żyrafy, słonie. 
Przekład wersu 30 autorstwa Roberta Besta wynika z transkrypcji tego wersu przyjętej przez Sima Parpolę - wybitnego badacza pisma klinowego:

lu-ú mit-hur ru-pu-us-sa ù mu-rak-ša (Gi XI 3024 .

Słowo mit-hur (Gi XI 30) stanowi pochodną rdzenia maharu - „przyjąć, uczynić równym”25. Specjalista ten uzyskał taką transkrypcję w wyniku interpretacji rysu — jako: hur. Sylabarz zamieszczony przez Nowickiego podaje dla tego rysu transkrypcję $b e^{26}$. Rys ten występuje również w wersie Gi XI 33, gdzie Simo Parpola transkrybuje go sylabą be. Istotna rozbieżność w interpretacji tego rysu w wersach Gi XI 30 (hur) oraz Gi XI 33 (be) przy równoczesnym potwierdzeniu wersji be w sylabarzu czyni wątpliwą interpretację tego rysu w Gi XI 30 jako jako hur. Zamiast mit-hur należy więc przyjąć transkrypcję mit-har, bowiem rys —-, który Simo Parpola odczytuje jako hur (w słowie mit-hur), posiada również transkrypcję har ${ }^{27}$. W Gi XI 30 występuje słowo mit-har. Jest to forma akadyjskiego mitharu będącego synonimem sumeryjskiego terminu $i b$-sis, który w matematyce sumeryjskiej posiadał znaczenie: „bok kwadratu” lub „pierwiastek kwadratowy” (tj. drugiego stopnia) ${ }^{28}$. Tak więc zapis:

lu-ú mit-har ru-pu-us-sa u mu-rak-ša (Gi XI 30) ${ }^{29}$

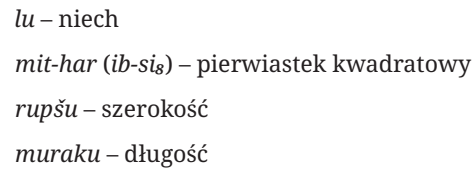

posiada znaczenie:

I niech jej szerokość i długość pierwiastkiem kwadratowym (Gi XI 30).

24 Cyt. za: S. Parpola, The Standard Babylonian Epic of Gilgamesh..., dz. cyt., s. 109.

25 S. Parpola, The Standard Babylonian Epic of Gilgamesh..., dz. cyt.

26 P. Nowicki, Pismo klinowe, język akkadycki. Zagadnienia podstawowe, Warszawa 1964, s. 8a.

27 L. W. King, Assyrian language. Easy lessons in the cuneiform inscriptions, London 1901, s. 91 (Books on Egypt and Chaldaea, 5).

28 Ibsi [square], [w:] The Pennsylvania Sumerian Dictionary, http://psd.museum.upenn.edu/epsd/ e2490.html.

29 Cyt. za: S. Parpola, The Standard Babylonian Epic of Gilgamesh..., dz. cyt., s. 109. 
Liczba, dla której Utnapisztim powinien obliczyć pierwiastek kwadratowy, jest podana nie w tym miejscu, lecz w wersie Gi XI 58: 10 ninda, tj. około $60 \mathrm{~m}$. Zatem łącznie zapis wersów Gi XI 30 oraz Gi XI 58 należy odczytać:

I niech arki szerokość oraz długość stanowią pierwiastek kwadratowy z 10 ninda.

\section{Translatorski problem redaktora Księgi Rodzaju}

Redaktor Księgi Rodzaju zaczerpnął elementy opisu potopu z literatury babilońskiej. Specjaliści wskazują zależność tego opisu od Eposu o Gilgameszu i Eposu o Atrahasisie. Można też wykazać zależność fragmentów biblijnego opisu potopu od sumeryjskiego dokumentu Recenzja z Nippur ${ }^{30}$ datowanego na początek II tysiąclecia ${ }^{31}$. Powyższe okoliczności czynią zasadnym przypuszczenie, iż redaktor ten nie stosował się do babilońskiej tradycji ustnej, lecz korzystał z dostępnych mu źródeł pisanych. Wymiary podane w Rdz 6, 15 redaktor tej księgi mógł więc zaczerpnąć z dokumentu sumeryjskiego Recenzja z Nippur. W opinii Samuela Noaha Kramera tekst tego dokumentu jest najbliższy biblijnemu opisowi potopu spośród znanych dokumentów sumeryjskich ${ }^{32}$. Z zapisanych na tablicy sześciu kolumn zawierających przypuszczalnie około 300 linii zachowało się tylko 71 linii - niektóre fragmentarycznie. Centralna część utworu wprowadza bohatera imieniem Ziusudra, któremu bóstwo oznajmia wiadomość o nieuchronnym potopie. Po tej wypowiedzi następuje uszkodzony fragment tablicy obejmujący około 40 linii zapisu klinowego. Następujący po tym uszkodzeniu fragment zawiera opis kataklizmu. Taka okoliczność pozwala domniemywać, iż na uszkodzonej części tablicy była zapisana instrukcja bóstwa dotycząca budowy arki, w tym jej wymiarów. Można więc przypuszczać, że autor Księgi Rodzaju zaczerpnął zapis Rdz 6, 15 $\mathrm{z}$ dostępnego mu dokumentu sumeryjskiego Recenzja z Nippur, który zawierał wymiary arki podane w sumeryjskiej terminologii matematycznej. Zapis tego dokumentu zawierał polecenie bóstwa o sumeryjskim znaczeniu:

30 Sumerian Myths and Epic Tales. The Deluge, translator S. N. Kramer, [w:] The ancient Near East, dz. cyt., t. 1, s. $42-44$.

31 Por. A. J. Obidowicz, Biblijny opis potopu a dokumenty mezopotamskie, art. cyt.

32 Por. Sumerian Myths and Epic Tales. The Deluge, translator S. N. Kramer, dz. cyt., s. 42. 
Niech będzie długość pierwiastkiem kwadratowym z 300 kuš.

Niech będzie szerokość pierwiastkiem kwadratowym z 50 kuš.

Niech będzie wysokość pierwiastkiem kwadratowym z 30 kuš.

Przełożenie tego zapisu na współczesne jednostki długości oznacza, że arka miała posiadać następujące wymiary:

- długość około $12 \mathrm{~m}$,

- szerokość około $5 \mathrm{~m}$,

- wysokość około $4 \mathrm{~m}$.

Obiekt pływający o takich wymiarach był wykonalny siłami wybrańca ocalonego przed potopem.

Z Rdz 7, 4 oraz Gi XI 76 wynika, że arka budowana była przez 7 dni, więc konstrukcja opisana według interpretacji akadyjskiej (60 m każda krawędź arki) oraz biblijnej (długość 300 łokci, szerokość 50 łokci, wysokość 30 łokci) była niemożliwa do wykonania w takim czasie siłami kilkuosobowego zespołu. Bóg działający w wydarzeniu potopu - niezależnie od imienia nadanego $\mathrm{Mu}$ przez autorów owych starożytnych zapisów - nie wymagał od swego wybrańca realizowania przedsięwzięcia nierealnego.

\section{Abstrakt}

\section{Arka Noego a opisy potopu w tekstach sumeryjskich i akadyjskich}

Artykuł zawiera nowe propozycje interpretacji i przekładu opowiadania o arce Noego zawartego w Księdze Rodzaju dotyczące budulca arki, a także jej wymiarów. Zdaniem autora artykułu wymiary arki podane w Księdze Rodzaju są zbyt duże, by kilkuosobowy zespół mógł ją zbudować w ciągu 7 dni. Ponieważ opis budowy arki autor biblijny zaczerpnął najprawdopodobniej ze starszego Eposu o Gilgameszu, w artykule podjęto próbę ustalenia jej wymiarów w oparciu o teksty sumeryjskie i akadyjskie oraz matematykę babilońską.

Słowa kluczowe: arka, Gilgamesz, język akadyjski, Księga Rodzaju, Noe, pismo klinowe, przekład, wymiary

\section{Abstract}

\section{Noah's Ark and Earlier Descriptions of the Flood in Sumerian and Akkadian Texts}

This article contains new suggestions for interpreting and translating the story of Noah's Ark in Genesis regarding the building material of the ark as well as its dimensions. According to the author of the article, the dimensions of the ark given in the book of Genesis are too large to have been built by a team of several people within seven days. Since the description of the ark's construction was probably taken 
from the older Epic of Gilgamesh, this article attempts to determine its dimensions based on Sumerian and Akkadian texts as well as Babylonian mathematics.

Keywords: Akkadian language, ark, cuneiform, dimensions, Genesis, Gilgamesh, Noah, translation

\section{References}

Best, R. M. (n.d.). Translation Errors in the Gilgamesh Flood Myth. Retrieved May 3, 2019, from https://www.noahs-ark-flood.com/gilgamsh.htm

Brzegowy, T. (1998). Pięcioksiag Mojżesza. Wprowadzenie i egzegeza Księgi Rodzaju 1-11. Wydawnictwo Diecezji Tarnowskiej Biblos.

D’jakonov, I. M. (1961). Ėpos o Gil'gameše ("O vse vidavšem»). Izdatel'stvo Akademii nauk SSSR. https://dlib.rsl. $\mathrm{ru} / 01004969646$

Juszkiewicz, A. P. (Ed.). (1975). Historia matematyki od czasów najdawniejszych do początku XIX stulecia. W trzech tomach: Vol. 1: Od czasów najdawniejszych do początku czasów nowożytnych (S. Dobrzycki, Trans.). Państwowe Wydawnictwo Naukowe.

King, L. W. (1901). Assyrian language. Easy lessons in the cuneiform inscriptions. K. Paul, Trench, Trübner \& Co. Kramer, S. N. (1963). The Sumerians. Their history, culture, and character. University of Chicago Press.

Kuśmirek, A. (Ed.). (2000). Księga Rodzaju. Hebrajsko-polski Stary Testament. Wydanie interlinearne z kodami gramatycznymi, transkrypcją oraz indeksem rdzeni. Oficyna Wydawnicza Vocatio.

Läpple, A. (1983). Od Księgi Rodzaju do Ewangelii. Wprowadzenie do lektury Pisma Świętego (J. Zychowicz, Trans.; 2nd ed.). Wydawnictwo Znak.

Neugebauer, O. (1935). Register, Glossar, Nachträge. In O. Neugebauer (Ed.), Mathematische Keilschrift-Texte (Vol. 2, pp. 1-64). Springer-Verlag Berlin Heidelberg GmbH. https://doi.org/10.1007/978-3-642-67893-6_1

Nowicki, P. (1964). Pismo klinowe, język akkadycki. Zagadnienia podstawowe. Akademia Teologii Katolickiej.

Obidowicz, A. (2004). Biblijny opis potopu a dokumenty mezopotamskie. Ruch Biblijny i Liturgiczny, 57(1), 5-10. https://doi.org/10.21906/rbl.482

Osanai, N. (2005). A Comparative Study of the Flood Accounts in the Gilgamesh Epic. Answers in Genesis. Retrieved May 3, 2019, from https://answersingenesis.org/the-flood/flood-legends/flood-gilgamesh-epic/

Parpola, S. (1997). The standard Babylonian Epic of Gilgamesh. Cuneiform text, transliteration, glossary, indices and sign list. The Neo-Assyrian Text Corpus Project.

Pismo Święte Starego i Nowego Testamentu w przekładzie z języków oryginalnych. Opracował zespót biblistów polskich z inicjatywy Benedyktynów Tynieckich (5th ed.). (2014). Wydawnictwo Pallotinum.

Plaut, W. G. (1974). The Torah. A modern commentary (Vol. 1). Union of American Hebrew Congregations.

Pritchard, J. B. (Ed.). (1978). Ancient Near Eastern Texts Relating to the Old Testament with Supplement. Princeton University Press. https://doi.org/10.2307/j.ctt19wccw4

The Pennsylvania Sumerian Dictionary. (n.d.). Retrieved May 3, 2019, from http://psd.museum.upenn.edu/ 